\title{
KNOWLEDGE AND ATTITUDE OF DOCTORS REGARDING EHEALTH USE IN A TERTIARY HEALTH CARE FACILITY OF BANGLADESH
}

\author{
Tasbeen Akhtar Sheekha ${ }^{1 *}$, Khorshed Ali Miah ${ }^{2}$ and Syed Jafar Raza Rizvi ${ }^{3}$ \\ ${ }^{1}$ Universal Medical College Research Center, Bangladesh \\ ${ }^{2}$ Department of Public Health and Hospital Administration, National Institute of \\ preventive and Social Medicine, Bangladesh \\ ${ }^{3}$ Johns Hopkins Center for Communication Programs, Bangladesh
}

\begin{abstract}
This paper presents a view to assess the level of knowledge and attitude of doctors regarding e-health in tertiary health care facility. It was a facility base cross-sectional study conducted among 150 doctors of 17 departments of Bangabandhu Sheikh Mujib Medical University (BSMMU), Dhaka in December 2015. A purposive sampling technique was done, and data were collected with a self-administered structured questionnaire. Chi-square test was done to find association between knowledge and attitudes. Around $62 \%$ respondents had correct knowledge about e-health with majority in telemedicine along with electronic medical records (EMR), electronic health record (EHR) and electronic prescribing. The doctors also showed positive attitudes (59\%) towards e-health. They think that EMR would reduce errors regarding treatment and telemedicine can access health care services for patients anywhere in the country, help remove the problem of shortage of doctors and can save money. There was strong association between knowledge and attitudes which was statistically significant $(\mathrm{p}=0.01)$. Resourceful and intensive educational session should be provided to the doctors to increase their knowledge in e-health. More researches are necessary to determine barriers to e-Health addressing lack of resources, high data management cost etc. which impact the implementation of e-Health programs.
\end{abstract}

Keywords: e-health, chi-square test, knowledge, attitude

\section{Introduction}

With the increase of wider use of mobile technology and internet, development of information technology-based health systems and applications gained importance. First used in 1999, E-health is a relatively modern term, referring to healthcare practice supported by electronic processes and communication. It refers to the healthcare practice supported by electronic processes and communication (Eysenbach, 2001). It is the application of computer, Internet, mobile phone and other technologies in order to improve patients' health status (Broderick, M. \& Smaltz, D.H., 2003) also deliver health care services with the help of various types of communications technologies, i.e. telemedicine, internet, electronic health records, mobile technology and clinical decision support (Ticia, G et al, 2010).

E-health initiative in Bangladesh started in 1999 in the Health \& Population sector Programs (HPSP) by the Ministry of Health \& Family Welfare (MOHFW) to boost up the efficiency of the program. In the year of 2011, the Government of Bangladesh (GOB) came up with a 5-year long Health, Population and Nutrition Sector Development Program (HPNSDP) for MOHFW which lead various government, non-government and private sector level to take e-health initiatives. It was consisting of total 32 operational plans including e-Health. Health service through internet, mobile phone, telemedicine service, complaints, suggestions and pregnancy care advice 
through SMS, online population health registry, GIS in health service, bulk SMS - available in government hospitals in Bangladesh (Health Bulletin, DGHS, 2012).

Most of the private clinics and hospitals in the Dhaka city are using their own database system for patient health records e.g. Apollo Hospital, Square Hospital, United Hospital, Medinova Hospital and Popular Diagnostic Center (Hoque et al., 2014). However, most of the physicians and nurses are not familiar with eHealth and its' benefit (Uddin, G et al, 2012) and A lot of physicians were skeptical of using eHealth systems (Nessa, A et al., 2008)

To implement eHealth effectively it is important to involve the physicians/doctors in the process which requires adequate knowledge and positive attitude. Hence, this study was designed to assess the knowledge and attitude of doctors regarding eHealth use in tertiary healthcare facility of Bangladesh.

\section{Authors' contribution:}

Dr. Sheekha T.A conceived the idea, developed the theory, collected data and performed the computations with the help of Syed Rizvi. All the authors discussed and verified the analytical methods. Dr. Khorshed Ali Miah supervised the paper from the beginning along with the findings of this work. All authors discussed the results and contributed to the final manuscript.

\section{Methodology}

The aim of the study was to assess the level of knowledge and attitude of doctors regarding e-health. This was a descriptive type of cross-sectional study. The duration of the study was 6 months from July 2015 to December 2015. The data collection was done at 17 different departments and from different specialty of three blocks (A, B \& C) of BSMMU. Doctors who were enrolled in Post-Graduation course were selected as the study population. Sample size was calculated by using the following formula: $\mathrm{z} 2 \mathrm{pq} / \mathrm{d} 2$

Where,

$$
\begin{aligned}
& n=\text { Asking sample size } \\
& z=\text { Level of confidence or level of significance } \\
& d=\text { Standard error } \\
& p=\text { Proportion in the population possessing the characteristic of interest }
\end{aligned}
$$

As no relevant estimate was found so it was assumed that $50 \%$ of general practitioners have knowledge about ehealth. So, the prevalence rate of knowledge and attitude regarding e-health was $50 \%$ resulting an overall $\mathrm{n}=384$. But considering the resource and time constraints, 150 participants were included in this study.

Respondents were recruited using purposive sampling. Doctors who were present during the data collection period and willing to participate were approached and requested to participate in the study. Data collection instrument was a semi structured, self-administered questionnaire. The questionnaire was developed using selected variables according to specific objectives. The questionnaire contained questions related to- i) General information of doctors, ii) knowledge regarding components of e-health iii) Attitude regarding components of ehealth. The questionnaire was pretested and then finalized after necessary modification according to the findings of pretesting. Before initiation of the interview, a verbal consent was received from the respondents after explaining the aims and objectives of the study, reason for invitation in this study, expectation from the respondents, risks and benefits, confidentiality of data etc. by the researcher. A complete assurance was given to them that all information provided by them would be kept confidential and their name or anything, which could 
identify them, would not be published or exposed anywhere. The respondents were given absolute freedom of withdrawing themselves at any point they wanted to. The researcher also assured the respondents that there would be no invasive procedure included in the study. Data processing and analysis was done using SPSS (Statistical Package for Social Sciences) version 22.0. A univariate analysis of the variables was performed, and chi square test was done to determine any association between knowledge and attitude. The results were presented in the form of tables and graphs. Data quality was strictly maintained in every stage of data collection, interpretation and analysis. If any discrepancy observed, it was soon corrected by enquiry at the original place of study. Tools and instruments were checked every day. At the end of each day of data collection, each questionnaire was checked to see whether it was filled up completely and consistently. The data entry was started immediately after completion of data collection. Limitation of the study included small sample size to give a comment about the population and increased chance of bias as the sampling technique was purposive sampling not random sampling.

\section{Results}

Table 1 Distribution of the Respondents according to the Demography $(n=150)$

\begin{tabular}{|c|c|}
\hline Age of the respondents in years & Percentage \\
\hline $25-29$ & $44.0 \%$ \\
\hline $30-34$ & $34.7 \%$ \\
\hline $35-39$ & $19.3 \%$ \\
\hline $40-44$ & $1.3 \%$ \\
\hline $45-49$ & $.7 \%$ \\
\hline Mean \pm SD & $31.02 \pm 3.77$ \\
\hline \multicolumn{2}{|l|}{ Gender } \\
\hline Male & $62 \%$ \\
\hline Female & $38 \%$ \\
\hline \multicolumn{2}{|l|}{ Graduation Degree of the doctors } \\
\hline MBBS & $63 \%$ \\
\hline BDS & $37 \%$ \\
\hline \multicolumn{2}{|l|}{ Nature of Duty } \\
\hline Full Time & $94 \%$ \\
\hline Part Time & $6 \%$ \\
\hline \multicolumn{2}{|l|}{ Length of Service } \\
\hline $1-5$ years & $63.3 \%$ \\
\hline $6-10$ years & $26.7 \%$ \\
\hline
\end{tabular}


$\begin{array}{ll}16-29 \text { years } & .7 \%\end{array}$

Table 1 shows that among the total respondents most (44\%) belonged to the age group 25-29 year. $62 \%$ of them were male and the rest were female. 63\% had Bachelor of Medicine and Bachelor of Surgery (MBBS) graduation and 37\% Bachelor of Dental Surgery (BDS) degree. Majority (94\%) of the respondents had full time job. $63.30 \%$ respondents were in service for $1-5$ years.
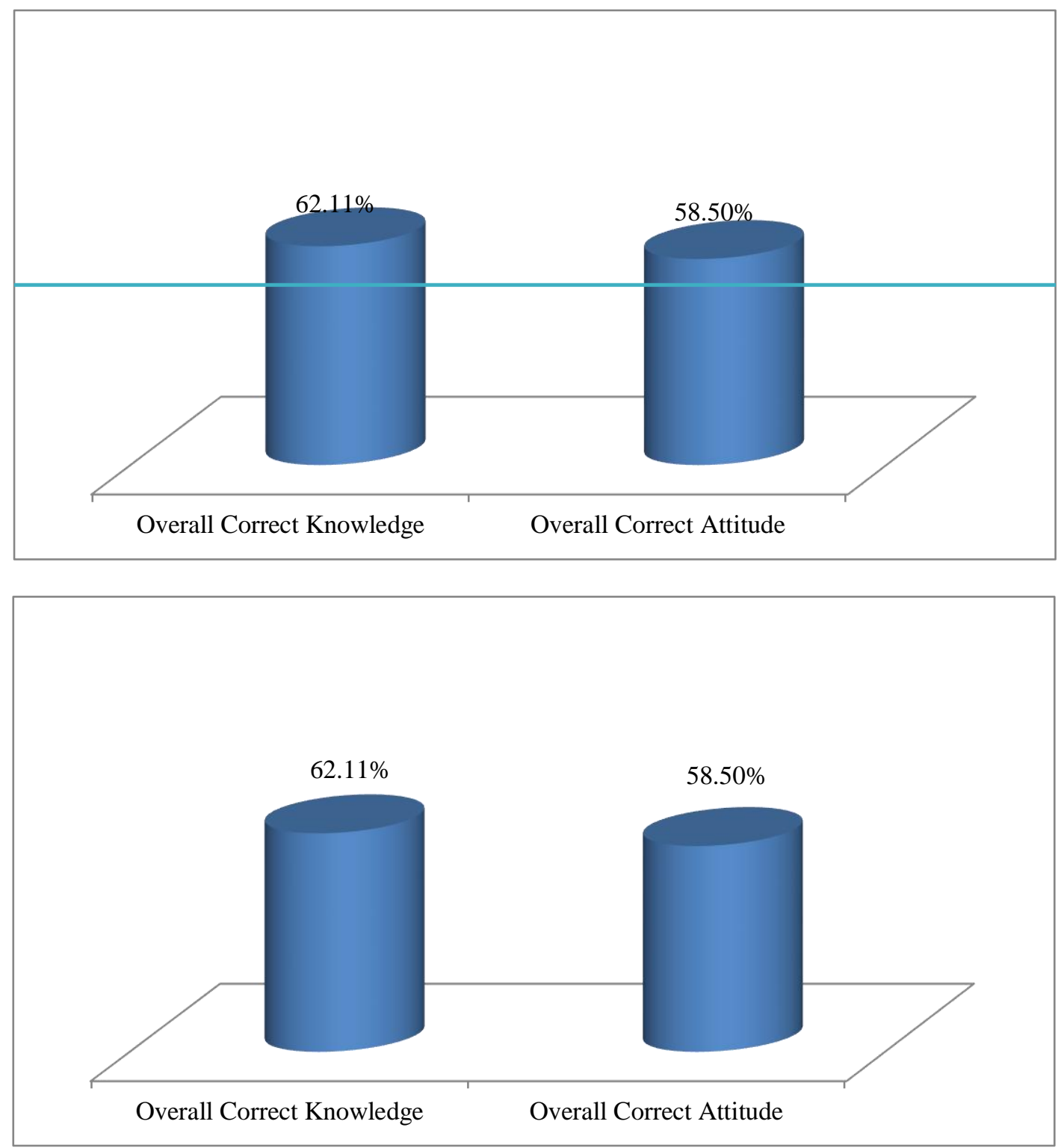

Figure 1 Distribution of the respondent according to overall knowledge and attitude $(n=150)$

Figure 1 presents that among the total respondents around $62 \%$ had correct knowledge and around $59 \%$ had positive attitude about eHealth. 

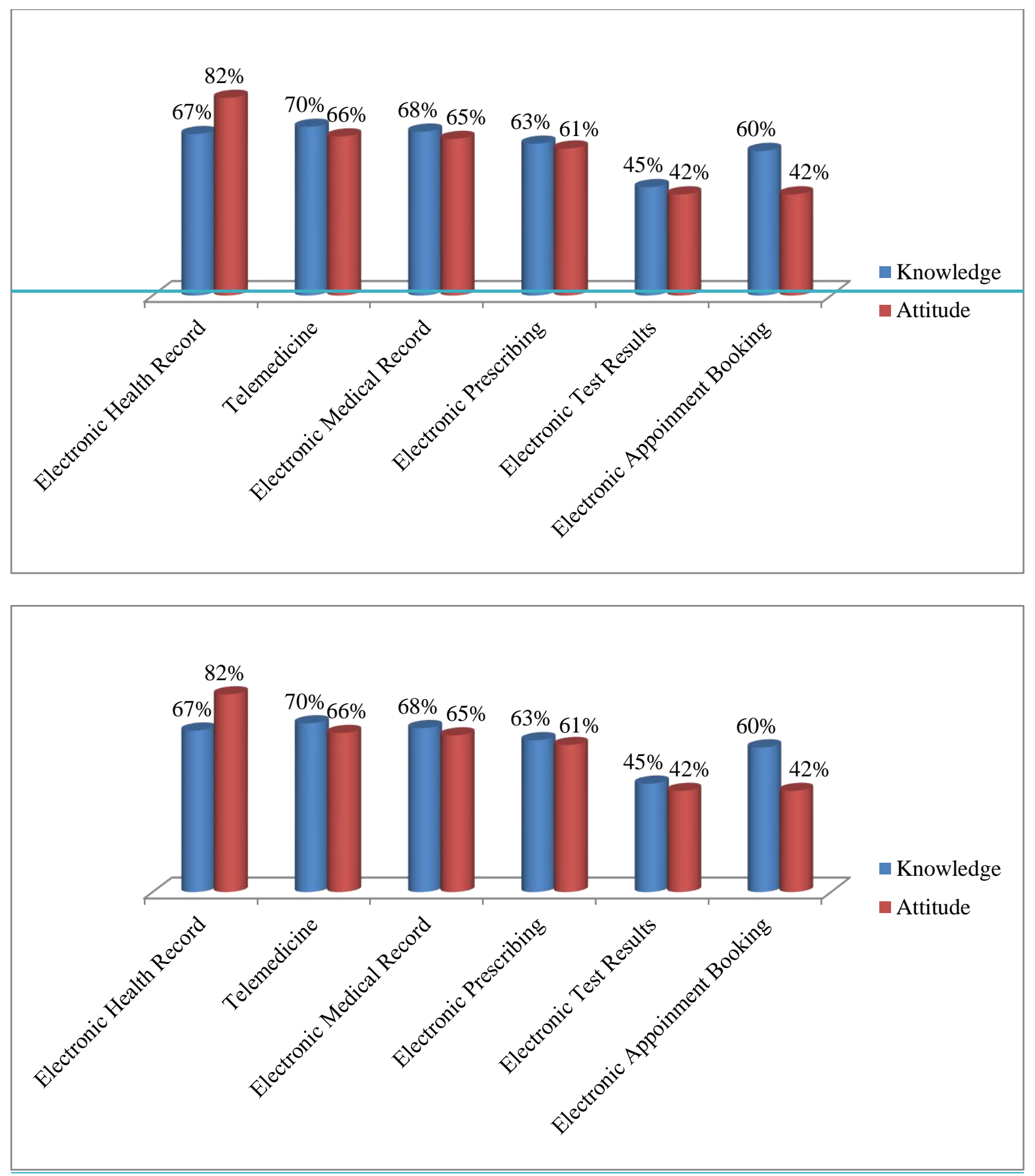

Figure 2 Knowledge about components of e-health (n=150)

Among the total respondents around $70 \%$ had correct knowledge about telemedicine, $68 \%$ about electronic medical record along with $67 \%, 63 \%$ and $60 \%$ in electronic health record, electronic prescribing and electronic appointment booking respectively. The respondents also showed positive attitude towards e- health. $82 \%$ had positive attitude towards electronic health records along with $66.1 \%, 65.6 \%, 61 \%, 42.6 \%$ and $42 \%$ in telemedicine, electronic medical records, electronic prescribing, electronic test result and electronic appointment respectively.

Table 2 Contingency table showing association between attitude and level of knowledge of the respondents 


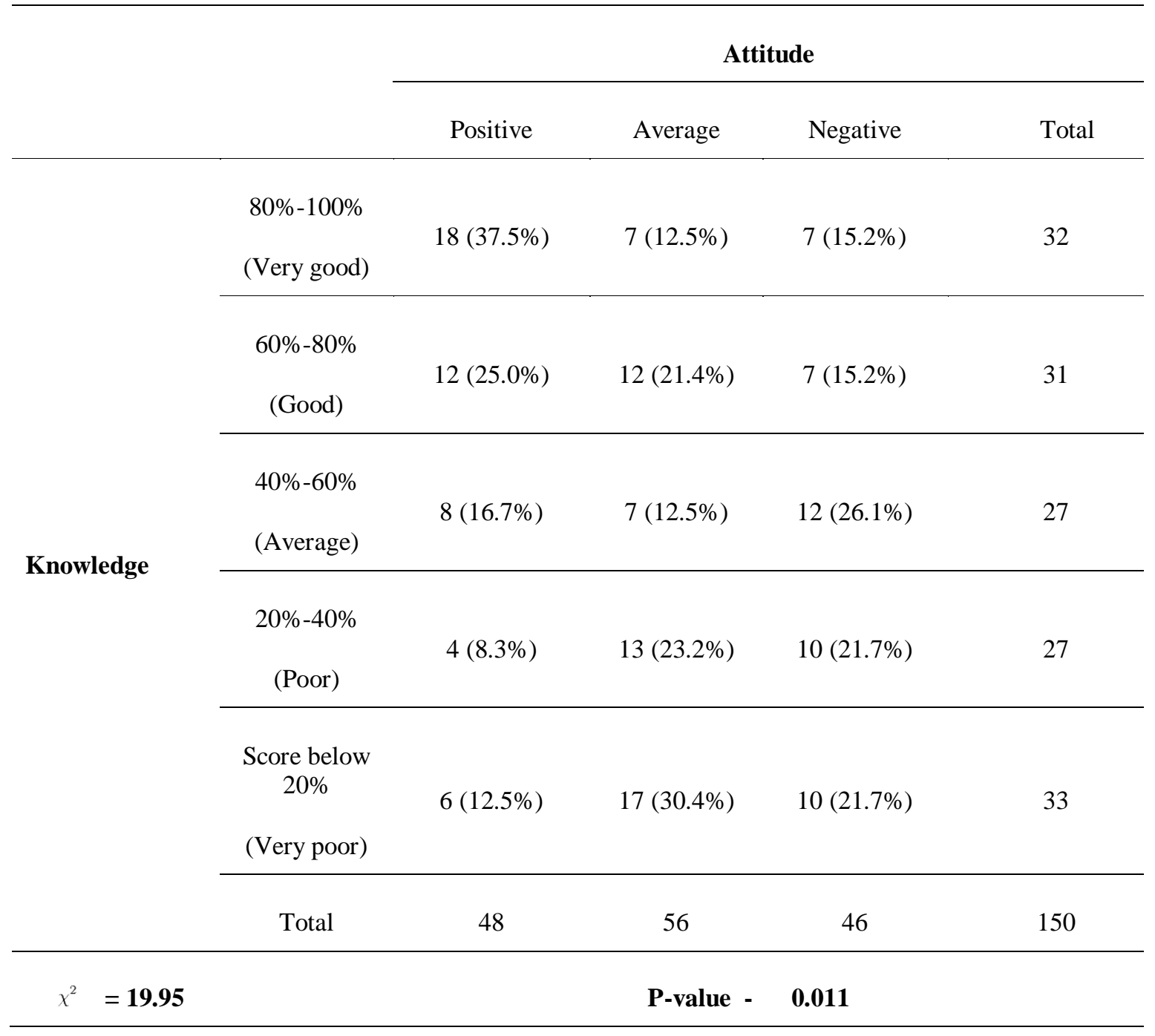

Table 2 shows that after scoring of the knowledge level it was found that $37.5 \%$ respondents were found to show positive attitude among those who had very good knowledge. It was also found that $12.5 \%$ respondents were found to show average attitude among those who had knowledge scoring from $40 \%-60 \%$. With a Pvalue of 0.011 , the result was found statistically significant.

\section{Discussion}

This was a descriptive cross-sectional study conducted among 150 doctors to assess the level of knowledge and attitudes regarding e- health and to determine the relationship between the level of knowledge and attitudes of doctors. On an average, 62.7 percent respondents had correct knowledge about e- health and approximately 59 percent had positive attitudes towards it. Chi- square test was done to find if there is any association between knowledge and attitude of the respondents. After conducting the test, it was found that the percentage of respondents whose positive attitude were higher also had very good knowledge while the percentage of respondents whose positive attitude was lower showcased very poor knowledge- meaning, attitude increases when level of knowledge is good and attitude decreases when level of knowledge is decreases. In conclusion, with a p-value 0.01 we can say that there is an association between knowledge and attitudes, and it is statistically significant.

In Bangladesh, the health care system is still going through its developmental process. To increase the efficiency in health care sector it is important to implement eHealth in every health care setting. In order to do this health care provider should have adequate knowledge as well as positive attitude towards it. Along with it, also study 
related to eHealth use in primary, secondary and tertiary level and barriers to eHealth use should be conducted. Intensive workshops and training session should be arranged for the Health care providers to increase knowledge, positive attitude and practice of eHealth.

\section{Acknowledgement}

This research was supported by National Institute of Social and Preventive Medicine (NIPSOM), Dhaka, Bangladesh.

\section{References}

Broderick, M., \& Smaltz, D.H., 2003, E-Health Defined. HIMSS E-Health SIG White Paper, Pace University.

Eysenbach, G., 2001, What Is E-Health?, Journal of Medical Internet Research, 3(2):e20.

Health Bulletin, 2012, Ministry of Health and Family Welfare, Government of the People's Republic of Bangladesh.

Hoque, Md., 2014, e-Health in Bangladesh: Current Status, Challenges, and Future Direction, The International Technology Management Review, Vol. 4 (2014), 87-96.

Nessa, A., Ameen, M., Ullah, S. Kwak, K., 2008, Applicability of Telemedicine in Bangladesh: Current Status and Future Prospects, The International Arab Journal of Information Technology (IAJIT), Vol. abs/0911.1, no. 2, pp. 138-145.

Ticia, G., Veronica, O., Karl, B., \& Ariel, P. M., 2010, An Agenda For Action On Global E-Health, Health affairs, Vol. 29, no.2, 233-236.

Uddin, G., 2012, E-governance of Bangladesh: Present Scenario, Expectation, Ultimate Target and Recommendation, International Journal of Scientific \& Engineering Research, 3(11), 2229-5518. 